\title{
Régimen jurídico de las obras huérfanas en España
}

Legal status of orphan works in Spain

\author{
José Luis GonZÁLEZ SAN JUAN \\ Abogado. C/ del Cáliz 15, 37001 Salamanca, España, \\ gonzalezsanjuan@icasal.com
}

\begin{abstract}
Resumen
Se analiza la problemática de las obras huérfanas, a través de una revisión crítica de su régimen jurídico en España. Después de repasar brevemente la protección general que otorgan los derechos de autor a las obras en España, se delimita el concepto de obra huérfana y se revisan las condiciones para que puedan ser utilizadas por las entidades beneficiarias. Se hace referencia también a la recientemente creada base de datos europea de obras huérfanas, que se encuentra aún en un estado muy incipiente. Finalmente, se ponen de manifiesto los principales inconvenientes que, a nuestro juicio, presenta el actual régimen jurídico de las obras huérfanas.

Palabras clave: Obras huérfanas. Derechos de autor. Aspectos jurídicos de la información y la documentación. Bases de datos de obras huérfanas. España.
\end{abstract}

\section{Introducción}

Los derechos de autor pretenden cohonestar los intereses de los creadores y los derechos de los usuarios, especialmente el del acceso a la cultura (Abbud y Fadel, 2010, p. 163), con el objetivo de incentivar la creación cultural, en beneficio de toda la sociedad.

Sin embargo, en algunas ocasiones, estos derechos de autor pueden ser un importante freno para preservar y difundir ciertos tipos de obras (Xalabarder, 2012, p. 2), como es el caso de las obras huérfanas, que son aquellas en las que, estando vigentes los derechos de autor, no se conoce quien es el titular de los mismos, o conociéndose no es posible contactar con él.

En este artículo, después de repasar brevemente algunos conceptos básicos del derecho de autor, plantearemos la problemática que suscitan las obras huérfanas, y revisaremos su régimen jurídico actual en España, centrándonos especialmente en los usos autorizados de las mismas, las entidades beneficiarias, y las condiciones para poder llevarlos a cabo.

\begin{abstract}
The problem of orphan works is analyzed, through a critical review of its legal regime in Spain. After reviewing briefly the general protection granted by copyright to works in Spain, the concept of orphan work is delimited, and its conditions are reviewed so that they can be used by the beneficiary entities. Reference is also made to the recently created European database of orphan works, which is still in a very incipient state. Finally, the main disadvantages of the current legal regime for orphan works are discussed.
\end{abstract}

Keywords: Orphan works. Copyright. Orphan work databases. Legal aspects of information work. Spain.

Finalmente, pondremos de manifiesto los principales inconvenientes que, a nuestro juicio, presenta el actual régimen jurídico de las obras huérfanas en España.

\section{Conceptos previos}

\subsection{Derechos de autor}

Los derechos de autor son la parte de la propiedad intelectual (1) que tiene por objeto las obras literarias y artísticas, incluyendo ciertas creaciones tecnológicas, como los programas de ordenador y las bases de datos.

Según la Organización Mundial de la Propiedad Intelectual (OMPI), protegen la forma concreta en la que se expresan las ideas (OMPI, 2007, p. 5 ), pero no a las ideas mismas, pues éstas deben fluir libremente (Carbajo, 2010, p. 128).

En el ordenamiento jurídico español, las obras quedan amparadas por los derechos de autor desde su creación, siempre que sean originales, con independencia de su calidad artística, musical, científica o literaria, y también de su valor comercial (OMPI, 2007, p. 6). 
Esta protección es automática, no siendo necesario el registro de las mismas, aunque sea conveniente hacerlo para probar la autoría y la fecha de creación.

El titular de estos derechos es la persona física que crea la obra (su autor), aunque nuestro ordenamiento extiende esta titularidad a algunas personas jurídicas, en ciertos casos concretos.

\subsection{Contenido de los derechos de autor}

El autor de una obra original, por el mero hecho de crearla, tiene dos tipos de derechos sobre ella: los derechos morales y los derechos de explotación (OMPI, 2007, p. 8).

Los derechos morales están orientados a salvaguardar la paternidad de la obra, son inalienables e irrenunciables, y no se pueden transmitir.

Se conceden únicamente a los autores que son personas físicas, y entre otros, son derechos morales los siguientes: a decidir sobre la divulgación de la obra, al reconocimiento de la autoría, a la integridad de la obra, etc.

Por otra parte, los derechos de explotación o patrimoniales tienen una naturaleza económica, y pueden ser transmitidos libremente, tanto a título oneroso como gratuito. Permiten al autor obtener una remuneración por el uso, disfrute o explotación que de su obra realicen terceros.

Los derechos económicos reconocidos a los autores en nuestro ordenamiento jurídico son los siguientes: reproducción, distribución, comunicación pública, transformación y compensación equitativa por copia privada.

\subsection{Límites de los derechos de autor}

Como ocurre con cualquier otro tipo de propiedad, los derechos de autor no son absolutos, sino que están sujetos a límites o excepciones.

Estos límites son la manifestación de la cláusula del Estado Social y Democrático de Derecho, esto es, de la función social de la propiedad (Carbajo, 2010, p 128), y resultan necesarios para lograr un justo equilibrio entre el derecho a la propiedad intelectual y el acceso a la información, que forma parte de las libertades de expresión y de información (Sturges, 2010, p. 21; González, 2016, p. 42).

Desde un punto de vista técnico jurídico, se configuran como limitaciones a los derechos de los autores (Riera, 2001, p. 118), aunque de facto funcionen como auténticos derechos subjetivos de los usuarios.

Hay dos tipos de límites. Por una parte existe un límite temporal general, que determina la cadu- cidad de los derechos de explotación con el transcurso del tiempo, pasando las obras a ser del dominio público.

En España, este límite general es de setenta años tras la muerte del autor, aunque existen plazos diferentes para algunos casos particulares (Martínez, 2014, p. 4-9).

Por otra parte, también se establecen excepciones a los derechos de autor, que permiten ciertos usos concretos de las obras, sin autorización de sus titulares y en las condiciones establecidas por la ley (probablemente la excepción más conocida sea la de copia privada).

Como estas excepciones limitan los derechos subjetivos de los autores, deben ser interpretadas siempre de forma restrictiva.

\section{Marco legal de las obras huérfanas}

Antes de delimitar el concepto de obra huérfana y analizar sus usos autorizados, enumeraremos las principales normas que resultan aplicables a las obras huérfanas en el ordenamiento jurídico español.

A nivel comunitario existe una norma específica para estas obras: la Directiva 2012/28/UE, de 25 de octubre de 2012, sobre ciertos usos autorizados de las obras huérfanas (DOUE, 2012).

La finalidad principal de esta directiva es facilitar la digitalización y posterior puesta a disposición del público de las obras huérfanas, con el objetivo de contribuir a difundir y preservar el acervo cultural de la Unión Europea (UE).

Esta directiva recoge prácticamente todas las recomendaciones realizadas en 2007 por la Federación Internacional de Entidades de Derechos de Reproducción (IFRRO), en su declaración sobre las obras huérfanas (Cedro, 2007).

Ya dentro del ámbito del Derecho interno español, las principales normas a tener en cuenta son las dos siguientes:

(a) Texto refundido de la Ley de Propiedad Intelectual (TRLPI), aprobado por RD Legislativo 1/1996, de 12 de abril (BOE, 1996), y recientemente modificado por la Ley 21/2014 (BOE, 2014), que transpuso la Directiva 2012/28/UE (DOUE, 2012), incorporando un nuevo límite específico para las obras huérfanas, en el art. 37 bis.

(b) Real Decreto (RD) 224/2016, de 27 de mayo, por el que se desarrolla el régimen jurídico de las obras huérfanas (BOE, 2016), que es un reglamento de desarrollo del art. 37 bis TRLPI (BOE, 1996), en el que además se transpusieron los aspectos de la Di- 
rectiva 2012/28/UE (DOUE, 2012), que no habían sido incluidos en el citado art. 37 bis.

\section{Obras huérfanas}

\subsection{Concepto de obra huérfana}

El art. 2.1 del RD 224/2016 (BOE, 2016), define obra huérfana como:

Obra cuyos titulares de derechos de propiedad intelectual no están identificados o, de estarlo, no están localizados a pesar de haberse efectuado una previa búsqueda diligente de los mismos.

Cuando exista coautoría, no podrá considerarse obra huérfana si al menos uno de los titulares de sus derechos está identificado y localizado (Xalabarder, 2012, p. 5).

En las obras huérfanas se da la paradoja de que, al estar vigentes los derechos de autor, se requiere autorización de su titular para cualquier uso de la obra, cuando, por la propia definición de obra huérfana, éste no es conocido o no está localizado (Martínez, 2014, p. 14).

De esta forma, se dificulta tanto su difusión como su preservación (Iglesias-Rebollo, 2012, p. 451), al limitarse la posibilidad de digitalizarla. Y, aunque es cierto que la digitalización no resuelve completamente el problema de la preservación (Abbud y Fadel, 2010), también lo es que resulta mucho más sencillo conservar y divulgar las obras digitalizadas.

\subsection{Distinción entre obras huérfanas, anónimas y descatalogadas}

Debemos diferenciar la obra huérfana de la obra anónima, ya que no son categorías equivalentes (Xalabarder, 2012, p. 5). No todas las obras huérfanas son anónimas (pues puede conocerse el autor, pero no ser posible localizarlo, o también conocerse el autor, pero no conocerse el titular actual de los derechos o no ser posible localizarlo), ni todas las obras anónimas son huérfanas (muchas obras anónimas están en el dominio público).

$Y$ finalmente, una obra huérfana es también diferente de una obra descatalogada, que es aquella cuyo titular no desea seguir explotándola, y que normalmente tendrá tanto autor como titular de derechos conocidos y localizados. No obstante, es cierto que las obras descatalogadas suscitan algunos problemas legales muy similares a los de las obra huérfanas.

\subsection{Estimación del número de obras huérfanas}

Aunque resulta muy complicado determinar el número total de obras huérfanas existentes en la UE, algunos autores han tratado de estimarlo, y parece existir un cierto consenso en que su número es elevado, y también en que las obras afectadas son principalmente obras de texto y fotografías (Riera, 2013, p. 11).

Tanto Arquero y Marco (2016, p. 367), como Raquel Xalabarder (2012, p. 3), hacen referencia a trabajos en el que se habla de unos $3 \mathrm{mi}-$ llones de libros huérfanos en la UE y de unas 225.000 obras cinematográficas, mientras que el número de fotografías huérfanas es muchísimo mayor, pues sólo en Reino Unido se estima que hay del orden de 17 millones.

\subsection{Adquisición de la condición de obra huérfana}

La condición de obra huérfana, y con ello la posibilidad de que sea utilizada para los usos autorizados, se adquiere una vez se haya finalizado una búsqueda diligente y de buena fe, sin que haya sido posible conocer el titular de los derechos, o bien conociéndose, no sea posible localizarlo, y este reconocimiento se extiende a toda la UE.

Los requisitos que debe cumplir dicha búsqueda están desarrollados en el RD 224/2016 (BOE, 2016), y básicamente consisten en intentar localizar la obra en una serie de registros y bases de datos, empezando por la base de datos de obras huérfanas de la UE, y que debe extenderse, como mínimo, a todos los enumerados en el anexo del citado RD.

La búsqueda también debe comprender las obras y otras prestaciones protegidas que estén insertadas o incorporadas en la obra huérfana inicial.

Aunque es posible subcontratar la búsqueda a una entidad privada, la responsabilidad de la correcta realización de la misma seguirá siendo, en todo caso, de la entidad beneficiaria.

Finalizada la búsqueda diligente, las entidades beneficiarias deberán archivar el expediente de la búsqueda y remitir a la autoridad nacional los resultados de la misma, así como registrarlos en la base de datos de obras huérfanas de la UE.

\subsection{Base de datos de obras huérfanas de la UE}

La Directiva 2012/28/UE (DOUE, 2012), establece la creación de una base de datos pública de obras huérfanas, única a nivel de la UE. Esta base de datos ha sido creada y está gestiona por la Oficina de Armonización del Mercado Interior de la UE, aunque actualmente se encuentra en un estado muy incipiente (Arquero y Marco, 2016, p. 384). 
A fecha de noviembre de 2016, se habían inscrito un total de 1.979 obras huérfanas, y solamente 14 de los 32 países posibles (2), entre los que no estaba España, tenían obras huérfanas declaradas (Arquero y Marco, 2016, p. 372).

No obstante, España ya había dado de alta a algunas entidades beneficiarias en dicha base de datos (Semjevki y Torres, 2016, p.12).

\subsection{Autoridad nacional competente}

Es la autoridad encargada de gestionar y centralizar, en cada Estado, todas las cuestiones relacionadas con las obras huérfanas.

En el caso de España, la autoridad nacional competente es la Subdirección General de la Propiedad Intelectual, del Ministerio de Educación, Cultura y Deporte, a tenor del art. 2.3 del RD 224/2016 (BOE, 2016).

\section{Usos autorizados}

\subsection{Entidades beneficiarias}

Las entidades beneficiarias son las únicas a las que la ley autoriza el uso de las obras huérfanas, y están enumeradas en el art. 2 del RD 224/2016 (BOE, 2016):

Los centros educativos, museos, bibliotecas, hemerotecas, archivos, fonotecas y filmotecas accesibles al público, ya sean de naturaleza pública o privada, así como los organismos de radiodifusión.

\subsection{Usos autorizados y condiciones}

La Directiva 2012/228/CE (DOUE, 2012), regula un nuevo límite, no sujeto a remuneración, para las obras huérfanas (Riera, 2013, p.9), que ha sido incorporado en el TRLPI mediante la introducción de un nuevo artículo, el 37 bis (BOE, 2014).

El art. 3.2 del RD 224/2016 (BOE, 2016), establece como únicos usos autorizados la reproducción y la puesta a disposición del público, siempre sin ánimo de lucro, y orientados a cumplir los fines relacionados con la misión de interés público de las entidades beneficiarias

Además, la obra debe haber sido publicada o radiodifundida por primera vez en un Estado miembro de la UE.

No obstante, las entidades beneficiarias podrán obtener ingresos, exclusivamente para cubrir los costes de la digitalización y puesta a disposición, y siempre que no los cubra en su totalidad otra institución, aunque no se determina claramente qué conceptos comprenden dichos costes (FESABID, 2015, p.2).

\subsection{Fin de la condición de obra huérfana}

El titular de los derechos sobre la obra huérfana podrá, en cualquier momento, solicitar a la autoridad nacional o a la entidad beneficiaria el fin de la condición de obra huérfana, presentando prueba suficiente de su titularidad, según lo establecido en el art. 6 del RD 224/2016 (BOE, 2016).

Tras la solicitud, la entidad beneficiaria deberá abstenerse de seguir utilizando la obra, salvo que el titular se lo autorice, y comunicará al responsable de la base de datos de obras huérfanas dicha situación, para que sea actualizada.

El titular de los derechos podrá solicitar una compensación equitativa a la entidad beneficiaria, por el uso realizado de su obra hasta ese momento, que será fijará teniendo en cuenta el uso concreto, su naturaleza no comercial y el perjuicio causado.

La cuantía se fijará de común acuerdo entre el titular de los derechos y la entidad beneficiaria, pero si no hubiera acuerdo, la determinará la autoridad nacional competente, previa consulta a la Sección Primera de la Comisión de la Propiedad Intelectual.

\subsection{Crítica a la regulación actual}

Si bien la Directiva 2012/28/UE (DOUE, 2012), junto con las normas que la transponen, han venido a llenar el vacío legal que existía en relación con las obras huérfanas, autorizando ciertos usos de las mismas, creemos que no se han solucionado completamente todos los problemas.

Coincidimos con la mayoría de los autores en que se trata de un régimen demasiado restrictivo (Aparicio, 2016, p. 7 y Riera, 2013, p. 11), que impone una elevada carga administrativa a las entidades beneficiarias, especialmente en lo relativo a la búsqueda diligente, y a su documentación (FESABID, 2015, p. 1).

La búsqueda diligente es demasiado compleja, carga toda la responsabilidad en la entidad beneficiaria, y requiere un tiempo y unos recursos económicos que muchas veces no estarán disponibles, lo que puede traducirse en un desincentivo, sobre todo teniendo en cuenta que sus resultados van a ser siempre inciertos.

Por otra parte, si aparece el titular de los derechos, la entidad beneficiaria no solamente pierde la posibilidad de recuperar la inversión realizada para digitalizar y poner a disposición la obra (pues ha de cesar inmediatamente en el uso), sino que además debe compensar al titular por los usos ya realizados. 
Además, este régimen jurídico deja muy poco margen a la iniciativa privada (Riera, 2013, p. 11), y creemos que hubiera sido muy positivo haber autorizado ciertos usos comerciales de las obras huérfanas, aunque condicionados a una compensación mayor si aparecieran los titulares.

El cálculo de la indemnización equitativa es problemático, pues ésta debe fijarse de común acuerdo entre el titular y la entidad beneficiaria, $y$ el RD 224/2016 (BOE, 2016) se limita a establecer unos criterios generales demasiado vagos, algo que puede ser una importante fuente de conflictos (FESABID, 2015, p. 5).

Por último, el art. 6.5 de la Directiva 2012/28/UE (DOUE, 2012), permite que los Estados miembros determinen libremente los criterios para el cálculo de dicha compensación, lo que puede dar lugar a una discriminación de los titulares de los derechos, que podrán ser compensados de forma diferente dependiendo del Estado concreto en que se haya utilizado la obra (Riera, 2013, p. 10).

\section{Conclusiones}

Aunque los derechos de autor son un mecanismo eficaz para lograr un justo equilibrio entre los derechos de los creadores y los de los usuarios, existen ocasiones en las que, como ocurre en el caso de las obras huérfanas, pueden ser un obstáculo para la preservación y difusión del patrimonio cultural.

La reforma promovida por la Directiva 2012/28/UE (DOUE, 2012), si bien ha sido un paso muy positivo para proteger nuestro acervo cultural, al facilitar la digitalización y puesta a disposición de las obras huérfanas, no soluciona adecuadamente todos los problemas suscitados por este tipo de obras.

Consideramos que se impone una importante responsabilidad y una elevada carga burocrática a las entidades beneficiarias, especialmente en lo relativo a la búsqueda diligente, que se nos antoja demasiado compleja.

Por otra parte, las entidades beneficiarias son las únicas que pueden utilizar las obras huérfanas, aunque hubiera sido muy positivo permitir algunos usos comerciales, convenientemente delimitados y con una mayor compensación equitativa, de forma que se permitiera la entrada a la iniciativa privada.

Opinamos que la legislación actual deja demasiado abierta la determinación de la cuantía de la compensación, lo que puede ser una importante fuente de conflictos.
Además, esta compensación puede actuar como un importante freno para las entidades beneficiarias, que deben compensar al titular y cesar el uso, perdiendo la posibilidad de recuperar las inversiones realizadas, cuando normalmente este titular habrá conocido o recordado la existencia de una obra olvidada, gracias a las gestiones y los usos realizados por las entidades beneficiarias.

A pesar de ello, valoramos positivamente esta reforma legislativa, pues es un importante paso en la dirección correcta, y sin duda contribuirá a preservar las obras huérfanas existentes en la UE, aunque sólo el tiempo nos dirá si los resultados son los esperados por el regulador.

También creemos que la digitalización y puesta a disposición de la gran cantidad de obras huérfanas existentes en España, permitirá el desarrollo de nuevos proyectos de preservación y difusión de nuestro acervo cultural, dentro del seno de las organizaciones que las custodian.

Finalmente, consideramos que es necesario establecer alguna solución similar, de lege ferenda, para las obras descatalogadas, puesto que presentan una problemática muy parecida a la de las obras huérfanas.

\section{Notas}

(1) Propiedad intelectual en sentido amplio, que incluye propiedad industrial y derechos de autor.

(2) Los 28 de la UE, y además Islandia, Liechtenstein, Noruega y Suiza.

\section{Referencias}

Abbud, José Carlos; Fadel, Bárbara (2010). Las leyes de derecho de autor y su relación con la preservación digital. // Ibersid. 4 (2010) 159-164. ISSN 1888-0967. http:// www.ibersid.eu/ojs/index.php/ibersid/article/view/3822 (2017-3-21).

Aparicio, Juan Pablo (2016). Propiedad intelectual y suministro de contenidos digitales. // InDret. 3.16 (Julio 2016). http://www.indret.com/pdf/1246.pdf (2017-3-16).

Arquero, Rosario; Marco, Gonzalo (2016). Análisis del estado de la declaración de obras huérfanas en Europa. // Revista general de información y documentación. 26:2 (2016) 365-385.https://revistas.ucm.es/index.php/RGID/ article/view/54707/49910 (2017-3-16).

BOE (1996). Real Decreto Legislativo 1/1996, de 12 de abril, por el que se aprueba el texto refundido de la Ley de Propiedad Intelectual, regularizando, aclarando y armonizando las disposiciones legales vigentes sobre la materia. // Boletín Oficial del Estado (BOE). 97 (22 de abril de 1996) 14369-14396.

BOE (2014). Ley $21 / 2014$, de 4 de noviembre, por la que se modifica el texto refundido de la Ley de Propiedad Intelectual, aprobado por Real Decreto Legislativo 1/1996, de 12 de abril, y la Ley 1/2000, de 7 de enero, de Enjuiciamiento Civil. // Boletín Oficial del Estado (BOE). 268 (5 de noviembre de 2014) 90404-90439.

BOE (2016). Real Decreto 224/2016, de 27 de mayo, por el que se desarrolla el régimen jurídico de las obras huér- 
fanas. // Boletín Oficial del Estado (BOE). 141 (11 de junio de 2016) 39229-39236.

Carbajo, Fernando (2010). Creación, edición y lectura en la sociedad de la información: entre la propiedad intelectual y el acceso a la cultura. // Pliegos de Yuste. 11-12 (2010) 127-134. ISSN: 1697-0512. http://www.pliegos deyuste.eu/n1112pliegos/pdfs/125-134.pdf (2017-3-15).

CEDRO (2007). Las <<obras huérfanas>>. // Boletín informativo. 60 (2007) 22-23. http://www.cedro.org/docs/ documentos/boletin60.pdf (2017-03-19).

DOUE (2012). Directiva 2012/28/UE del Parlamento Europeo y del Consejo, de 25 de octubre de 2012, sobre ciertos usos autorizados de las obras huérfanas. // Diario Oficial de la UE (DOUE). 299 (27 de octubre de 2012) $5-12$

FESABID (2015). Comentarios al Borrador de Real Decreto, por el que se desarrolla el Régimen Jurídico de las obras huérfanas [Recurso en línea]. http://www.fesabid. org/sites/default/files/repositorio/2015_rd_obras huerfan as.pdf (2017-3-21).

González, José Luis (2016). Neutralidad de la red. // Ibersid 10:2 (2016) 39-44. ISSN 1888-0967. http://www.ibersid. eu/ojs/index.php/ibersid/article/view/4308. (2017-3-25).

Iglesias-Rebollo, César (2012). Derecho e información. // El profesional de la información. Vol. 21-5 (2012) 449-452. ISSN 1386-6710. http://recyt.fecyt.es/index.php/EPI/ article/view/epi.2012.sep.01 (2017-3-19).

Martínez, Pablo (2014). Guía de propiedad intelectual en la digitalización de obras de bibliotecas universitarias [Recurso en línea]. Universidad de Murcia. https://digitum. um.es/xmlui/bitstream/10201/37646/1/GU\%C3\%8DA\%2 ODE\%2OPROPIEDAD\%20INTELECTUAL\%20EN\%20L A\%20DIGITALIZACI\%C3\%93N\%20DE\%20OBRAS\%20 DE\%20BIBLIOTECAS\%20UNIVERSITARIAS.pdf (20173-21).
OMPI (2007). Principios básicos del derecho de autor y los derechos conexos. /Publicación de la Organización Mundial de la Propiedad Intelectual (OMPI) $n^{\circ}$ 909(S). http://www.wipo.int/edocs/pubdocs/es/wipo_pub_909.pdf (2017-3-17).

Riera, Patricia (2013). La solución europea a las obras huérfanas: la Directiva 2012/28/UE. // Diario La Ley. 8128 (2013) 8-12. ISSN 1989-6913.

Riera, Patricia (2001). Derechos de autor y acceso a la información: los conflictos en la era digital, Anuari de Biblioteconomia, Documentació i Informació: Bibliodoc 2001/2002 113-122. ISSN 1885-0685. http://www.raco. cat/index.php/Bibliodoc/article/view/16640/16482 (20173-20).

Semjevski, Nicole; Torres, José Vicente (2016). Base de datos de obras huérfanas. // II Jornadas sobre propiedad intelectual e industrial, Madrid, 26 de abril de 2016. http://www.oepm.es/export/sites/oepm/comun/document os_relacionados/Ponencias/101_06_II_Jornadas_Sobre _Propiedad_Intelectual_e_Industrial.pdf (2017-3-19)

Sturges, Paul (2010). Misterio y transparencia: el acceso a la información en los dominios de la religión y la ciencia. // Ibersid. (2010) 21-28. ISSN 1888-0967. http://www. ibersid.eu/ojs/index.php/ibersid/article/viewFile/3863/ 3643 (2016-7-15).

Xalabarder, Raquel (2012). Las obras "huérfanas" y las obras descatalogadas. // Noticias de la Unión Europea. (octubre 2012). Núm. monográfico sobre propiedad intelectual y sociedad de la información (coordinador Fernando Carbajo). ISSN: 2254-9080.

Enviado: 2017-03-27. Segunda versión: 2017-07-31 Aceptado: 2017-09-05. 